\title{
Congenital disorders in South Africa: A review of Child Healthcare Problem Identification Programme (Child PIP) mortality data, 2005 - 2017
}

\author{
M Patrick, ${ }^{1} \mathrm{MB}$ ChB, DCH (SA), FCPaed (SA); H Malherbe, ${ }^{2}$ PhD, MSc; C Stephen, ${ }^{3}$ MB ChB, DCH (SA); D Woods, ${ }^{4}$ MB ChB, MD, FRCP; \\ C Aldous, ${ }^{2} \mathrm{PhD}$ \\ ${ }^{1}$ Grey's Hospital, Pietermaritzburg, South Africa; and School of Clinical Medicine, Nelson R Mandela School of Medicine, College of Health \\ Sciences, University of KwaZulu-Natal, Durban, South Africa \\ ${ }^{2}$ School of Clinical Medicine, Nelson R Mandela School of Medicine, College of Health Sciences, University of KwaZulu-Natal, Durban, South Africa \\ ${ }^{3}$ Department of Paediatrics and Child Health, Faculty of Health Sciences, University of Cape Town and Red Cross War Memorial Children's \\ Hospital, Cape Town, South Africa \\ ${ }^{4}$ Department of Child and Adolescent Health, Faculty of Health Sciences, University of Cape Town, South Africa
}

Corresponding author: M Patrick (mark.patrick@kznhealth.gov.za)

\begin{abstract}
Background. Congenital disorders (CDs) form a major challenge for those affected, and for the structuring of services around their health needs. In South Africa (SA) the size and nature of the problem are unknown because reporting of CDs has been unreliable.

Objectives. To ascertain the occurrence and spectrum of congenital disorders in children dying in SA hospitals participating in the Child Healthcare Problem Identification Programme (Child PIP).

Methods. Child PIP has been used for auditing in-hospital childhood deaths in children's wards in SA state hospitals since 2005. By 2017, over 60000 audited deaths had been entered into the Child PIP database. We searched this database for CD occurrence and spectrum. Results. The number of deaths where a CD diagnosis was given as the Main Cause of Death was 243, 0.4\% of all-cause mortality. In 1678 deaths, CDs were assigned as an Underlying Condition, a 2.8\% occurrence. A diagnosis of CD was assigned 1968 times, indicating an overall CD burden in the children who died of 3.2\%, many children having more than one CD diagnosis. The spectrum of CDs was wide, with CDs of the heart being most prominent.

Conclusions. These new data paint a broad picture of the $\mathrm{CD}$ challenge that confronts the SA health system, a challenge that will increase in importance with the current decline in infectious diseases.
\end{abstract}

S Afr Med J 2018;108(8):647-653. DOI:10.7196/SAMJ.2018.v108i8.12980

Congenital disorders (CDs) are abnormalities of structure or function present at birth. ${ }^{[1]}$ The impact of CDs on quality of life and life expectancy is wide and varied. Some are lethal in utero, soon after birth, or later in life with no available medical cure (e.g. cystic fibrosis). Others are life-limiting in the absence of intervention but potentially curable (e.g. many cardiac anomalies), or require lifelong intervention (e.g. myelomeningocele). Others are minor, having no impact on quality of life or life expectancy (e.g. isolated polydactyly). As a group of conditions, they form a major challenge for those affected and for the structuring of services around their particular health needs.

In South Africa (SA), the size and nature of the problem are unknown because reporting of $\mathrm{CDs}$ has been unreliable. Inaccurate assessment and under-reporting have led to an underestimate of the contribution of CDs to the burden of disease. ${ }^{[2]}$

Keeping track of healthcare services required for a population in epidemiological transition is challenging. SA experienced positive epidemiological transition during the mid-20th century, with decreasing child mortality due to infections, and increasing life expectancy ${ }^{[3]}$ In the 1990s, the HIV/AIDS epidemic reversed these trends ${ }^{[4]}$ Successful implementation of prevention of mother-to-child transmission of HIV, the comprehensive roll-out of highly active antiretroviral therapy and other general interventions for improving child healthcare contributed to a return to positive transition in the early 2000s. ${ }^{[5,6]}$ Today, SA faces a quadruple disease burden (HIV/
AIDS, chronic diseases, poverty-related conditions and injuries) that includes both communicable and non-communicable diseases. ${ }^{[7,8]}$

In $\mathrm{SA}$, the burden of $\mathrm{CDs}$ has been hidden beneath the toll of infectious disease. ${ }^{[9]}$ With greater control of infectious diseases in the 1990s, before the HIV/AIDS epidemic exploded, CDs began to emerge as a public health challenge. However, the overwhelming health priorities of HIV/AIDS and concomitant tuberculosis obscured the issue of CDs once again. ${ }^{[9]}$ Although significant reductions were achieved in infant and child mortality from 2006 to 2011, these rates have since levelled off, suggesting that non-HIV issues require attention. ${ }^{[5,10-12]}$ One such issue is CDs. SA's infant mortality rate is currently 27 per 1000 live births, ${ }^{[13]}$ a figure well below 40 per 1000 , the level at which countries usually need to allocate resources to medical genetic services for the care and prevention of CDs, to significantly further reduce child mortality. ${ }^{[14-18]}$

One of the major barriers to the implementation of comprehensive services for the care and prevention of CDs is the limited information on their contribution to the burden of disease. ${ }^{[12]}$ The Second National Burden of Disease Study ${ }^{[19]}$ attributes $2.4 \%$ of neonatal deaths and a total of $4.2 \%$ of under- 5 deaths to congenital causes. However, these causes were limited to physical abnormalities (obvious malformations, deformities and chromosomal abnormalities present at birth) as defined in chapter XVII of the International Statistical Classification of Diseases and Related Health Problems, 10th revision (ICD-10), ${ }^{[20,21]}$ which excludes $\sim 40 \%$ of CDs (e.g. single-gene CDs, 
including metabolic disorders) that are scattered elsewhere in the ICD-10 system. ${ }^{[22]}$ When comprehensive and accurate empirical data are lacking, many countries use modelling to estimate the $\mathrm{CD}$ burden and to plan required services. ${ }^{[22]}$ The National Department of Health in SA uses a national surveillance system for assessing the prevalence of specific CDs. The observed CDs as reported in this system are much fewer than expected from modelled data. ${ }^{[2]}$

The Child Healthcare Problem Identification Programme (Child PIP) has been used for auditing in-hospital childhood deaths in children's wards in SA state hospitals since 2005, with the main purpose of improving the quality of healthcare for children. ${ }^{[23]}$ By 2017, >60 000 audited deaths had been entered into the Child PIP database (unpublished Child PIP data, May 2017). Eighty-eight percent of these deaths were in the under-5-year age category. This included neonates, who made up $8 \%$ of the deaths (Table 1). For each death the Child Death Data Capture Sheet (CDDCS) (Appendix 1) is completed. Information describing the circumstances of death, availability of records, referral information, nutritional status, HIV status and cause of death is included, as well as any possible modifiable factors in the care the child received.

For 'Cause of Death' three variables are recorded, viz. 'Main Cause of Death, 'Other Important Diagnoses' and 'Underlying Condition'.

\section{Objectives}

This report is a review of CD-related deaths identified in the Child PIP database. It provides an opportunity to assess the overall mortality burden of CDs recorded in facility-based childhood deaths in SA. Assessing the occurrence and spectrum of CDs in these deaths may assist in health service planning for children with CDs.

\section{Methods}

The number of SA state hospitals conducting mortality review using Child PIP increased from 26 in 2005 to $>245$ in 2017, representing $75 \%$ of state hospitals.

\section{Main Cause of Death}

One diagnosis per child death is allowed for Main Cause of Death (Appendix 1, CDDCS). The cause of death code is selected from the

\begin{tabular}{ll} 
Table 1. Core data, 2005 - 2017 & \\
\hline & $\boldsymbol{n}(\%)$ \\
\hline Provinces & $9(100)$ \\
Districts & $49(94)$ \\
Hospitals & $245(75)$ \\
Admissions & 2036316 \\
Audited deaths with age distribution & \\
$\quad 0-7$ days & $1900(3)$ \\
$8-28$ days & $2719(5)$ \\
28 days - 1 year & $32179(53)$ \\
1 - 5 years & $16098(27)$ \\
5 - 13 years & $6499(11)$ \\
$13-18$ years & $458(1)$ \\
Unknown & $722(1)$ \\
$\quad$ Total & $60575(100)$ \\
CD as Main Cause of Death (mortality) & $243(0.4)$ \\
Children with CD as Underlying & $1678(2.8)$ \\
Condition at death & $1968(3.2)$ \\
CDs recorded in children who died & \\
(burden of disease) & \\
CD = congenital disorder. &
\end{tabular}

Child PIP Cause of Death (CoD) Code List (Appendix 2), which is an abbreviated list based loosely on the ICD-10. ${ }^{[21]}$ It contains the most common conditions affecting SA children. The options for coding specific CDs are limited to Congenital Infections, Congenital Heart Disease and Congenital Malformations of the Respiratory System.

\section{Other Important Diagnoses}

Up to four Other Important Diagnoses may be entered, using the same CoD Code List referred to previously (Appendix 2).

For conditions not specifically included in the CoD Code List, for both 'Main Cause of Death' and 'Other Important Diagnoses', a number of nonspecific codes grouped by body system may be selected, e.g. 'Other Nervous System (Specify)'. For each of these, a specific diagnosis may be entered in an additional free-text field. Lists of 'Other (Specify)' free-text values were generated and searched by the authors for entries considered to be CDs. These data were analysed, along with the values Congenital Infections, Congenital Heart Disease and Congenital Malformations of the Respiratory System.

\section{Underlying Condition}

Underlying Condition allows one option for each child death to be selected from a short list of eight possible coded conditions (Appendix 2). This list includes the option 'Birth Defects'. Similar to 'Main Cause of Death' and 'Other Important Diagnoses', a more specific diagnosis can be entered as an additional free-text field against Underlying Condition entries. A list of free-text values for Underlying Condition was generated, searched for entries considered to be CDs and analysed, along with the variable 'Birth Defects'.

The generated free-text lists were 'short-listed' for CDs and verified by the authors until consensus was reached for inclusion or exclusion from the data set. Conditions were found to fall into two groups: those that were definitely included, such as trisomy 13 or truncus arteriosus, and those where there was some doubt, such as biliary atresia.

The CDs were then grouped into 10 broad categories: congenital infections (not HIV); inherited blood disorders/solid tumours; inherited metabolic disorders; CDs of the central nervous system; CDs of the respiratory system; CDs of the heart; CDs of the gastrointestinal tract; CDs of the genitourinary tract; chromosomal disorders; and not otherwise specified, multiple, skeletal. Data were recorded on a spreadsheet (Appendix 3) for analysis using simple counts and proportions.

Extracted CD data enabled:

- An estimate of CD-related mortality in the study population using Main Cause of Death (MCoD), i.e. children dying because of a $\mathrm{CD}$, as a proportion of all-cause mortality: [(No. dying with $\mathrm{CD}$ as $\mathrm{MCoD}) /($ Total no. dying)]

- An estimate of overall CD occurrence in the study population using Underlying Condition (UC), i.e. children dying with a CD, as a proportion of all children dying: [(No. dying with $\mathrm{CD}$ as $\mathrm{UC}$ )/ (Total no. dying)]

- An estimate of $\mathrm{CD}$ disease burden in the study population by using $\mathrm{MCoD}$ and Other Important Diagnoses (OIDs) combined, i.e. $\mathrm{CD}$ diagnoses made as a proportion of all children dying: $[(\mathrm{CD}$ diagnoses [MCoD + OIDs])/(Total no. dying)]

- A description of the spectrum of CDs in the study population.

\section{Ethical considerations}

This dataset consisted of aggregated country data. The data were anonymous, with no patient or facility identifiers. The study was given ethical clearance by the University of KwaZulu-Natal Biomedical Research Ethics Committee (ref. no. BE575/17). 


\section{Results}

Of the 2036316 admissions between January 2005 and April 2017, there were 60575 deaths audited and recorded in the Child PIP database.

\section{CD mortality}

The number of deaths where a CD diagnosis was given as the Main Cause of Death was $243,0.4 \%$ of all-cause mortality.

\section{CD occurrence}

CDs were assigned as an Underlying Condition in 1678 , a $2.8 \%$ occurrence.

\section{CD burden of disease}

Combining Main Cause of Death and Other Important Diagnoses, a diagnosis of CD was assigned 1968 times, with some children having more than one $\mathrm{CD}$ diagnosis, indicating an overall $\mathrm{CD}$ burden of $3.2 \%$.

\section{CD spectrum}

For the 1678 children who died with a $\mathrm{CD}$ as an Underlying Condition, 505 had a specific free-text diagnosis entered. The spectrum of CDs in this group of 505 is illustrated in Fig. 1.

For the combined Main Cause of Death and Other Important Diagnoses where $1968 \mathrm{CDs}$ were assigned, the CD spectrum is illustrated in Fig. 2.

\section{Discussion}

This review of the Child PIP database has provided an opportunity to evaluate the occurrence and spectrum of CDs in facility-based deaths of children admitted to SA state hospitals participating in the Child PIP mortality review process, between 2005 and 2017. The nature of the data, and the fact that this was a retrospective review, enabled new, although broad, brushstrokes of the $\mathrm{CD}$ picture in SA.

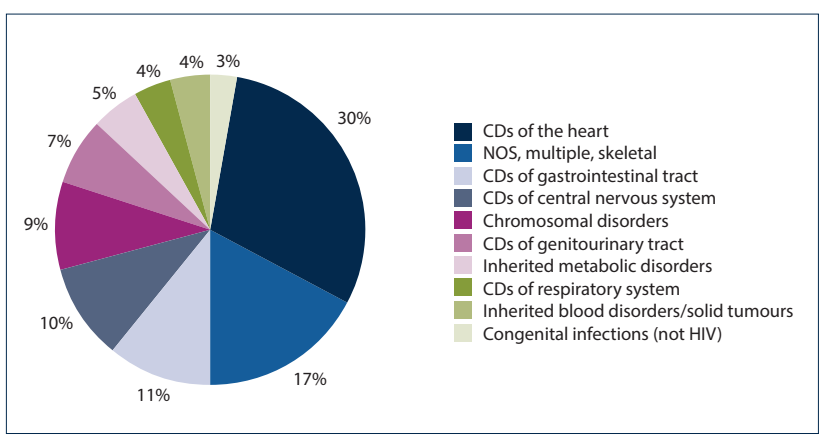

Fig. 1. Children dying with a $C D$ as an Underlying Condition, where specified $(\mathrm{N}=505)$. ( $C D=$ congenital disorder; NOS = not otherwise specified. $)$

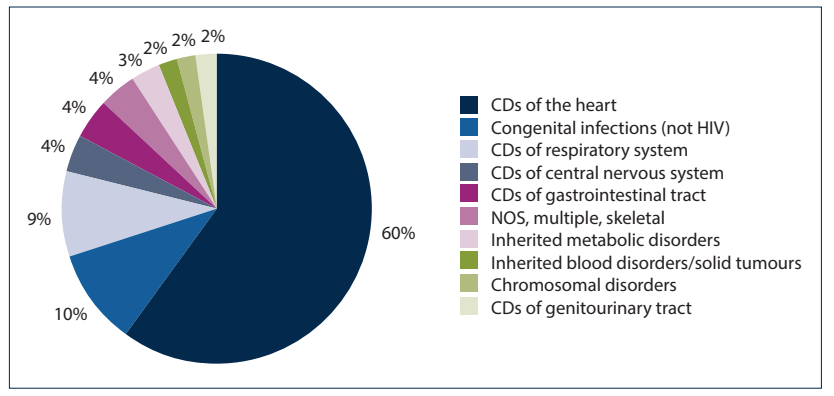

Fig. 2. CD occurrence as a Main Cause of Death or Other Important Diagnosis in children who died $(\mathrm{N}=1$ 968). ( $C D=$ congenital disorder; $N O S=$ not otherwise specified.)
For every 1000 children who died, four died as a direct result of a CD. For every 1000 children who died, 27 had one or more CDs, and for every 1000 deaths, the diagnosis of $\mathrm{CD}$ was made 33 times.

A wide spectrum of CDs was demonstrated (Figs 1 and 2), with CDs of the heart being the most prominent, followed by CDs of the respiratory system (Fig. 2). This preponderance may partly be due to the specification of these two as options in the CoD Code List.

These pooled data provide an indication of the magnitude and nature of the health challenge posed by CDs. Although $30 \%$ of child deaths from severe CDs in the first year of life cannot be prevented, $40 \%$ can be cured (mainly surgically). In addition, mortality data represent only the tip of the iceberg of the $\mathrm{CD}$ challenge. A further $30 \%$ of children with CDs will have disability ameliorated and quality of life improved through appropriate treatment. ${ }^{[24,25]}$ Services for children with CDs need to evolve to address both improving cure rates and therefore survival, and to provide for those surviving with lifelong mental, physical, auditory and/or visual special needs. ${ }^{[26]}$

Apart from the broader public health implications highlighted by this study, the CD spectrum information offers subspecialty services an evidence base for improving resource allocation and development for children with CDs falling into a subspecialist category. For example, CDs of the heart are strikingly prevalent, already suggesting a need for urgent attention.

This study confirms that as a group of conditions, CDs form a major challenge for those affected and for the structuring of services around their particular health needs. These findings are likely to be an underestimate of this health challenge for the following reasons:

- Not included in the Child PIP database are deaths occurring in hospitals that do not conduct mortality review using Child PIP ( $25 \%$ of state hospitals and all private hospitals).

- Deaths occurring in maternity sections of hospitals (labour wards and nurseries) are not audited in the Child PIP process; they are included in the Perinatal Problem Identification Programme (PPIP) database.

- In many of the larger state hospitals, the surgical disciplines do not participate in the Child PIP mortality review process.

- CDs may not have been recognised by clinical staff.

- Even when present, a CD may not have been assigned as a cause of or contributor to death (for example, a child with a severe congenital heart defect may have had pneumonia at the time of death, with this given as the Main Cause of Death, rather than the heart defect).

- The Child PIP CoD List itself has limited options for CD assignment.

- As Child PIP is facility-based, deaths occurring in the community are not included.

The study findings and these limitations point towards an urgent need for a more detailed assessment of CDs, with regard to both occurrence and spectrum.

The next version of Child PIP will start to address this need. The improved cause of death classification and more comprehensive coding options for $\mathrm{CDs}$ in the CoD Code List, and the ability to analyse $\mathrm{CD}$ data over time and by health district, will enhance Child PIP's ability to contribute to our understanding of the epidemiology of CDs in SA.

However, future research also requires wider collaboration between all repositories of $\mathrm{CD}$ data, such as PPIP, provincial CD notification systems and Statistics South Africa, to obtain a more complete picture. Attempts should also be made to fill CD information gaps, such as private sector and community-based deaths. Our study, which relied heavily on the analysis of free-text data, illustrates 
further that future researchers need to consider improving the construction of, data entry into, and data management in established and to-be-established information repositories. This is a challenge for all health information repositories, not only for Child PIP.

Future research that answers the need for an improved and more detailed assessment of CDs in SA will enable better planning for the provision of services to children and adults with CDs.

\section{Conclusions}

With a paucity of information on the occurrence and spectrum of CDs in SA, it is likely that medical genetic services for the care and prevention of CDs are inadequate with regard to both financial and human resources. These new data paint a broad picture of the $\mathrm{CD}$ challenge that confronts the SA health system, a challenge that will increase in magnitude as infectious diseases decline.

It is through an improved epidemiological understanding of CDs (by strengthening and co-ordinating CD information repositories) that better diagnosis and care of affected individuals through health worker training will become possible, and appropriate planning of effective and accessible CD services can be undertaken, with appropriate urgency.

Acknowledgements. The authors thank the Child PIP National Executive Committee for permission to use the national Child PIP dataset and express gratitude to Prof. Arnold Christianson for his initial contribution to and promotion of this project.

Author contributions. MP (lead author): concept, data extraction and analysis, write up; $\mathrm{HM}$ (co-author): $\mathrm{CD}$ expert, data analysis, write up; CS (co-author): mortality review expert, data analysis, write up; DW (co-author): CD expert, data analysis, write up; CA (senior author): $\mathrm{CD}$ expert, data analysis, write up.

Funding. None.

Conflicts of interest. None.

1. World Health Organization. Management of Birth Defects and Haemoglobin Disorders: Report of a Joint WHO-March of Dimes Meeting, Geneva, Switzerland, 17 - 19 May 2006. Geneva: WHO, 2006. 2. Lebese L, Aldous C, Malherbe H. South African congenital disorders data, 2006 - 2014. S Afr Med J 2016;106(10):992-995. https://doi.org/10.7196/SAMJ.2016.v106i10.11314

3. Omran AR. The epidemiologic transition: A theory of the epidemiology of population change. Milbank Mem Fund Q 1971;49(4):509-538. https://doi.org/10.2307/3349375
4. Kahn K, Garenne ML, Collinson MA, Tollman SM. Mortality trends in a new South Africa: Hard to make a fresh start1. Scand J Public Health 2007;35(69 Suppl):26-34. https://doi. org $/ 10.1080 / 14034950701355668$

5. Kerber K, Lawn J, Johnson L, et al. South African child deaths 1990 - 2011: Have HIV services reversed the trend enough to meet Millennium Development Goal 4? AIDS 2013;27(16):2637-2648. https://doi. org/10.1097/01.aids.0000432987.53271.40

6. Madhi S, Bamford L, Ngcobo N. Effectiveness of pneumococcal conjugate vaccine and rotavirus vaccine introduction into the South African public immunisation programme. S Afr Med J 2014;104(3):228-234. https://doi.org/10.7196/SAMJ.7597

7. Bradshaw D, Groenewald P, Laubscher R, et al. Initial Burden of Disease Estimates for South Africa, 2000. Cape Town: Medical Research Council, 2003.

8. Frenk J, Bobadilla J, Sepúlveda J, Cervantes M. Health transition in middle-income countries: New challenges for health care. Health Policy Plan 1989;4(1):29-39. https://doi.org/10.1093/heapol/4.1.29

9. Malherbe HL, Christianson AL, Aldous C. Need for services for the care and prevention of congenital disorders in South Africa as the country's epidemiological transition evolves. S Afr Med J 2015;105(3):186-188. https://doi.org/10.7196/SAMJ.9136

10. Dorrington R, Bradshaw D, Laubscher R, Nannan N. Rapid Mortality Surveillance Report 2013. Cape Town: South African Medical Research Council, 2014.

11. Dorrington R, Bradshaw D, Laubscher R, Nannan N. Rapid Mortality Surveillance Report 2014. Cape Torrn: South African Medical Research Council, 2015.
Tow

12. Malherbe H, Aldous C, Woods D, Christianson A. The contribution of congenital disorders to child malherbe H, Aldous C, Woods D, Christianson A. The contribution of congenital disorders to child
mortality in South Africa. In: Padarath A, King J, Mackie E, Casciola J, eds. South African Health Review 2016. 19th ed. Durban: Health Systems Trust, 2016:137-152.

13. Dorrington R, Bradshaw D, Laubscher R, Nannan N. Rapid Mortality Surveillance Report 2015. Cape Town: South African Medical Research Council, 2016.

14. World Health Organization. Community Approaches to the Control of Hereditary Diseases. Report of a WHO Advisory Group, Geneva, 3 - 5 October 1985. Geneva: WHO, 2005.

15. World Health Organization. Primary Health Care Approaches for the Control of Congenital Disorders and Disability. Report of a WHO meeting, Cairo, 6 - 8 December 1999. WHO/HGN/WG/00.1. Geneva: WHO, 2000

16. Christianson A, Modell B. Medical genetics in developing countries. Annu Rev Genomics Hum Genet 2004;5:219-265. https://doi.org/10.1146/annurev.genom.5.061903.175935

17. Alwan A, Modell B. Recommendations for introducing genetics services in developing countries. Nat Rev Genet 2003;4(1):61-68. https://doi.org/10.1038/nrg978

18. Christianson A. Community genetics in South Africa. Community Genet 2000;3:128-130. https://doi. org/10.1159/000051122

19. Msemburi W, Pillay-van Wyk V, Dorrington R, et al. Second National Burden of Disease Study for South Africa: Cause-of-death Profile for South Africa, 1997 - 2010. Cape Town: South African Medical South Africa: Cause-of-death Profile for South Africa, 1997 - 2010. Cape Town: South African Medical Research Council, 2014

20. Pillay-van Wyk V, Laubscher R, Msemburi W, et al. Second South African National Burden of Disease Study: Data Cleaning, Validation and SA NBD List. Cape Town: Burden of Disease Research Unit, South African Medical Research Council, 2014.

21. World Health Organization. International Statistical Classification of Diseases and Related Health Problems. 10th revision. Geneva: WHO, 1992

22. Modell B, Darlison M, Moorthie S, Blencowe H, Petrou M, Lawn J. Epidemiological Methods in Community Genetics and the Modell Global Database of Congenital Disorders (MGDb). UCL Discovery, 2016. http://discovery.ucl.ac.uk/1532179/ (accessed 16 July 2017).

23. Stephen C. Saving Children 2012 - 2013: An Eighth Survey of Child Healthcare in South Africa. Pretoria: Child Healthcare Problem Identification Programme, MRC Unit for Maternal and Infant Health Care Strategies, 2016

24. Czeizel A, Intôdy Z, Modell B. What proportion of congenital abnormalities can be prevented? BMJ 1993;306:499-503. https://doi.org/10.1136/bmi.306.6876.499
196eizel A, Inty Z, Modell B. What proportion of congenit

25. World Health Organization. Control of Hereditary Diseases: Report of a WHO Scientific Group 1993, World Health Organization. Control of Her
Geneva, Switzerland. Geneva: WHO, 1996 .

26. Christianson A, Howson C, Modell B. March of Dimes: Global Report on Birth Defects, the Hidden Toll of Dying and Disabled Children. New York: March of Dimes Birth Defects Foundation, 2006.

Accepted 1 March 2018 


\section{Appendix 1. Child Death Data Capture Sheet}

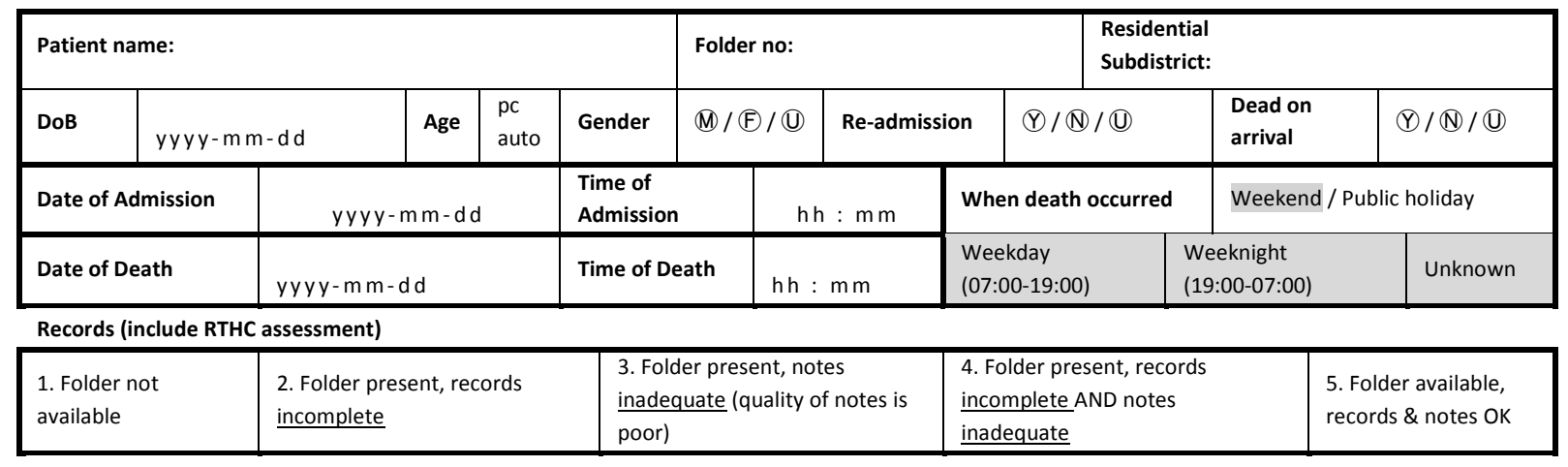

Referred

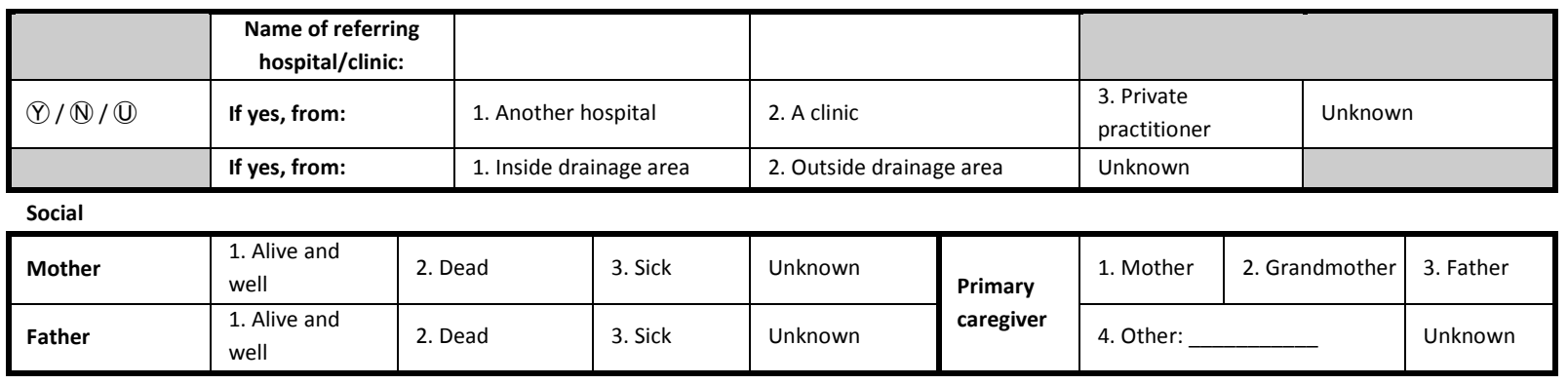

Nutrition (tick one category box, then fill in actual weight)

\begin{tabular}{|l|l|l|l|l|l|l|l|}
\hline 1. OWFA & 2. Normal & 3. UWFA & $\begin{array}{l}\text { 4. } \\
\text { Marasmus }\end{array}$ & 5. Kwashiorkor & 6. M-K & Unknown & Weight \\
\hline
\end{tabular}

HIV \& AIDS (enter status at time of admission, not at time of audit: this is NOT a post-mortem assessment)

\begin{tabular}{|l|l|l|l|l|l|l|l|}
\hline Lab & 1. Negative & 2. Exposed & 3. Infected & 4. No result & $\begin{array}{l}\text { 5. Not tested } \\
\text { (but indicated) }\end{array}$ & $\begin{array}{l}\text { 6. Not tested } \\
\text { (not indicated) }\end{array}$ & $\begin{array}{l}\text { Unknown } \\
\text { Clinical }\end{array}$ \\
\hline Perinatal ARV & 1. Stage I & 2. Stage II & 3. Stage III & 4. Stage IV & $\begin{array}{l}\text { 5. Not staged } \\
\text { (but indicated) }\end{array}$ & $\begin{array}{l}\text { 6. Not staged } \\
\text { (not indicated) }\end{array}$ & Unknown \\
\hline $\begin{array}{l}\text { Feeding in } \\
\text { first } 6 \text { months }\end{array}$ & 1. Exclusive breast for 6/12 & 2. No breast, ever & 3. Mixed, from birth & Unknown \\
\hline Cotrimoxazole & 1. Current & 2. Ever & $\begin{array}{l}\text { 3. Never (but } \\
\text { indicated) }\end{array}$ & 4. Never (not indicated) & Unknown \\
\hline ART (child) & 1. Current & 2. Ever & $\begin{array}{l}\text { 3. Never (but } \\
\text { indicated) }\end{array}$ & 4. Never (not indicated) & Unknown \\
\hline ART (mother) & 1. Current & 2. Ever & $\begin{array}{l}\text { 3. Never (but } \\
\text { indicated) }\end{array}$ & 4. Never (not indicated) & Unknown \\
\hline
\end{tabular}

Cause of Death (insert codes)

\begin{tabular}{|l|l|l|l|l|}
\hline Main cause of death: & \multicolumn{2}{l|}{ Underlying condition (if any): } \\
\hline Other important diagnoses $(\max 4):$ & & & & \\
\hline
\end{tabular}

Modifiable Factors (insert codes)

\begin{tabular}{|c|c|c|c|c|c|c|c|}
\hline \multirow[t]{2}{*}{ Code } & Ward: Hospital & \multicolumn{2}{|r|}{ Comments } & Code & \multicolumn{2}{|c|}{ Referring Facility \& Transit } & Comments \\
\hline & Probable & Possible & & & Probable & Possible & \\
\hline & Probable & Possible & & & Probable & Possible & \\
\hline & Probable & Possible & & & Probable & Possible & \\
\hline & Probable & Possible & & Code & Clinic/Ou & tients & Comments \\
\hline & Probable & Possible & & & Probable & Possible & \\
\hline \multirow[t]{5}{*}{ Code } & Admission & \& Emergen & : Hospital Comments & & Probable & Possible & \\
\hline & Probable & Possible & & Code & Home & & Comments \\
\hline & Probable & Possible & & & Probable & Possible & \\
\hline & Probable & Possible & & & Probable & Possible & \\
\hline & Probable & Possible & & & Probable & Possible & \\
\hline
\end{tabular}

In your opinion, had the process of caring been different, would this death have been avoidable?

\begin{tabular}{|l|l|l|l|}
\hline 1. Yes & 2. Not sure & 3. No & Unknown \\
\hline
\end{tabular}




\section{Appendix 2. Cause of Death Code List}

\begin{tabular}{|c|c|c|}
\hline Category & Causes of Death & Code \\
\hline \multirow{15}{*}{ Infections and Parasitic Diseases } & Acute diarrhoea, hypovolaemic shock & 101 \\
\hline & Chronic diarrhoea & 102 \\
\hline & Dysentery & 103 \\
\hline & TB: Pulmonary & 110 \\
\hline & TB: Meningitis & 111 \\
\hline & TB: Miliary, other extra-pulmonary & 112 \\
\hline & Septicaemia, possible serious bacterial infection & 120 \\
\hline & Congenital Infections (not HIV) & 130 \\
\hline & Meningitis: bacterial & 140 \\
\hline & Meningitis: viral (meningo-encephalitis) & 141 \\
\hline & Other inflammatory disease of CNS (e.g. abscess) & 142 \\
\hline & Measles & 150 \\
\hline & Other possible serious viral infection & 151 \\
\hline & Malaria & 170 \\
\hline & Hospital-acquired infection & 180 \\
\hline \multirow{3}{*}{ Oncology, Haematology } & Tumours, Leukaemias & 201 \\
\hline & Anaemia & 202 \\
\hline & Other (specify) & 203 \\
\hline \multirow{3}{*}{ Endocrine, Nutritional, Metabolic } & IDDM, DKA & 301 \\
\hline & Hypoglycaemia & 304 \\
\hline & Other (specify) & 305 \\
\hline \multirow{2}{*}{ Nervous System } & Status epilepticus & 401 \\
\hline & Other (specify) & 402 \\
\hline \multirow{6}{*}{ Circulatory System } & RHD, Rheumatic fever & 501 \\
\hline & Heart failure, Pulmonary oedema & 502 \\
\hline & Myocarditis & 503 \\
\hline & Congenital Heart Disease, Cardiomyopathy & 504 \\
\hline & Endocarditis & 505 \\
\hline & Other (specify) & 506 \\
\hline \multirow{7}{*}{ Respiratory System } & Croup & 601 \\
\hline & Pneumonia, LRTI (ARI) & 602 \\
\hline & PCP (suspected or confirmed) & 603 \\
\hline & Pneumothorax, Pyothorax, Pleural effusion & 604 \\
\hline & Asthma & 605 \\
\hline & Congenital malformations of the respiratory system & 606 \\
\hline & Other respiratory failure (specify) & 607 \\
\hline \multirow{3}{*}{ Digestive System } & Cirrhosis, Portal Hypertension, Liver Failure, Hepatitis & 701 \\
\hline & Surgical (appendix, hernia, intestines, peritoneum) & 702 \\
\hline & Other (specify) & 703 \\
\hline \multirow{4}{*}{ Genito-urinary System } & Acute nephritis & 801 \\
\hline & Acute renal failure & 802 \\
\hline & Chronic renal disease & 803 \\
\hline & Other (specify) & 804 \\
\hline III-defined / Unknown Cause & Ill-defined / Unknown causes of mortality & 900 \\
\hline Other Diagnosis & Other diagnosis (specify) & 901 \\
\hline Burns & Burns & 1000 \\
\hline \multirow{3}{*}{ Poisonings } & Paraffin & 1101 \\
\hline & Corrosives & 1102 \\
\hline & Other (specify) & 1103 \\
\hline Bites and Stings, Toxic plants & Bites and stings, Toxic plants & 1200 \\
\hline Inhalation / Aspiration & Inhalation of foreign body or gastric contents & 1300 \\
\hline \multirow{2}{*}{ Accidents } & Transport-related accidents & 1400 \\
\hline & Other accidents (incl. Drowning; specify) & 1500 \\
\hline Non-accidental injury, Abuse & Non-accidental injury, Abuse-related, Neglect & 1600 \\
\hline Homicide & Homicide & 1700 \\
\hline Suicide & Suicide & 1800 \\
\hline \multicolumn{2}{|l|}{ Underlying Conditions } & Code \\
\hline \multicolumn{2}{|l|}{ Cerebral palsy } & 1 \\
\hline \multicolumn{2}{|l|}{ Hydrocephalus } & 2 \\
\hline \multicolumn{2}{|c|}{ Birth defect (preconception = chromosomal/genetic or post conception e.g. foetal alcohol syndrome) } & 3 \\
\hline \multicolumn{2}{|l|}{ Ex-low birthweight / preterm infant } & 4 \\
\hline \multicolumn{2}{|l|}{ Twin / Multiple pregnancy } & 5 \\
\hline Other (specify) & & 10 \\
\hline
\end{tabular}




\section{Appendix 3. Congenital Disorders Data Capture Sheet}

Core Data: 2005-2017

\begin{tabular}{|l|l|l|}
\hline Item & No & \% \\
\hline Provinces & & \\
\hline Districts & & \\
\hline Hospitals & & \\
\hline Admissions & & \\
\hline Audited deaths and age distribution & & \\
\hline CD as main cause of death (mortality) & & \\
\hline Children with CD as underlying condition at death (prevalence) & & \\
\hline CDs recorded in children who died (burden of disease) & & \\
\hline
\end{tabular}

Children dying with CD as the main mause of death: Mortality

\begin{tabular}{|l|l|l|}
\hline CD Group & No & \% \\
\hline CDs of central nervous system & & \\
\hline CDs of the heart & & \\
\hline Inherited metabolic disorders & & \\
\hline CDs of gastro-intestinal tract & & \\
\hline NOS, multiple, skeletal & & \\
\hline Inherited blood disorders/solid tumours & & \\
\hline CDs of genito-urinary tract & & \\
\hline Chromosomal disorders & & \\
\hline Congenital infections (not HIV) & & \\
\hline CDs of respiratory system & \\
\hline
\end{tabular}

Children dying with CD as Underlying Condition: Prevalence

\begin{tabular}{|l|l|l|}
\hline CD Group & No & $\%$ \\
\hline CDs of the heart & & \\
\hline NOS, multiple, skeletal & & \\
\hline CDs of gastro-intestinal tract & & \\
\hline CDs of central nervous system & & \\
\hline Chromosomal disorders & & \\
\hline CDs of genito-urinary tract & & \\
\hline Inherited metabolic disorders & & \\
\hline CDs of respiratory system & & \\
\hline Inherited blood disorders/solid tumours & & \\
\hline Congenital infections (not HIV) & & \\
\hline & & \\
\hline UC Birth defects & \\
\hline UC BDs Specified in OS list & \\
\hline
\end{tabular}

CD occurrence in children who died: Burden of disease

\begin{tabular}{|l|l|l|}
\hline CD Group & No & $\%$ \\
\hline CDs of the heart & & \\
\hline Congenital infections (not HIV) & & \\
\hline CDs of respiratory system & & \\
\hline CDs of central nervous system & & \\
\hline CDs of gastro-intestinal tract & & \\
\hline NOS, multiple, skeletal & & \\
\hline Inherited metabolic disorders & & \\
\hline Inherited blood disorders/solid tumours & & \\
\hline Chromosomal disorders & & \\
\hline CDs of genito-urinary tract & & \\
\hline
\end{tabular}

